\title{
CHOOSING THE MOST ECONOMICALLY ADVANTAGEOUS SOLUTION TO THE DECISION OF THE ISSUE
}

\author{
Violeta Keršuliené ${ }^{1}$, Jūratė Butkienè ${ }^{2}$ \\ ${ }^{1}$ Faculty of Business Management, Vilnius Gediminas Technical University, \\ Sauletekio al. 11, Vilnius, Lithuania \\ ${ }^{2}$ Faculty of Creative Industries, Vilnius Gediminas Technical University, \\ Sauletekio al. 11, Vilnius, Lithuania \\ E-mails: ${ }^{1}$ violeta.kersuliene@vgtu.lt (corresponding author); ${ }^{2}$ jurate.butkiene@vgtu.lt
}

\begin{abstract}
Countries in conflict, trying to make a resolution, encounter a decision process. Often, in practice decisions are made based on groundless rationalization, therefore it is commonly believed that it is experience and intuition that are key to the decision making process. Since decisions in law are usually based on logical reasoning, taking into account conflict circumstances and facts, the success of this decision can be determined with mathematical calculation. In recent decades, as the boundries between scholarly disciplines blur, new ones are formed, which are not entirely indepedent, but bring in new research methods. Law and economics is a clear example of this interdisciplinery relation. The law system impacts the economical atmosphere, therefore before taking decision in law, economical aspects must be evaluated. Striving to resolve the disputes between parties at work mathematical calculations are used in order to analyze the expected behaviour of each party. Guidance for parties having dispute is the most economically viable option for completing the dispute.
\end{abstract}

Keywords: dispute, decision making, negotiation, game theory.

JEL Classification: C70, K10, K41.

\section{Introduction}

Legal decision-making process is based on a logical analysis of circumstances and facts related to a dispute, therefore mathematical calculations may be applied as a rationale for such decisions (Bielen, Peeters, Marneffe, \& Vereeck, 2017; Bench-Capon \& Prakken, 2008; Schweizer, 2016; Okudaira, 2018). The research carried out lately in analysing possible ways for employing the game theory in negotiation process (Ayuso, Bermudez, \& Santolino, 2015; Murtoaro \& Kujala, 2007), mitigation of risk of contingent litigation costs (Yoojung, Hastak, \& Cho, 2017; Brophy, 2014; Cooter \& Rubinfeld, 1989; Heyes, Rickman, \& Tzavara, 2004) allows employing mathematical methods in decision-making processes.

Any assessment of a choice of possible dispute resolution methods should refer to a number of indicators defining the purpose of the process covering any dispute resolution procedures, as well as dispute resolution and the decision execution. When selecting a dispute selection method the purpose needs to be defined in terms of several indicators (confidentiality, operativeness, maintaining of friendly relations, economic efficiency), therefore an important problem is a reconciliation of the values of the indicators that are often are contradictory (Zhang, Gong, \& Chiclana, 2017, p. 2017). In a most simple case efforts are made to combine all the indicators into one single common indicator. Mathematics offers several methods for coining such common indicator. One of the methods is based on a principle that the common indicator is a fraction with the indicators to be increased (the freedom of disposing of the dispute, confidentiality, friendly relations, satisfaction with the outcome of the dispute, etc.) in the numerator, and the indicators to be decreased (time costs, litigation costs, etc.) in the denominator. However, this method is sufficiently accurate for the purpose of selecting a dispute resolution method, because it is based on an assumption that all indicator are equally important, whereas in reality, subject to the nature of the dispute, the parties most often consider some indicators more important that others.

Other mathematical methods used for the purpose of establishing a common indicator are more advantageous, as they take into account the importance (weight) coefficient to each indicator. 
The common indicators produced by way of those methods would be ideal provided it were possible to accurately define the weight coefficients of the indicators. Ordinarily, parties to a dispute are able to comment on the importance of each indicator in very abstract terms only, therefore the duty of defining the possible limits of the coefficients lies with an advocate consulting the Parties regarding the selection of the dispute resolution methods, or another person authorised to take the decision.

It should be noted that taking decisions by referring to the most economically efficient and rational dispute resolution method is a sufficiently complex process, and only rarely can be assessed by a single common indicator, because in reality a single absolutely right solution does not exist. The problem has been addressed in their papers of a number of authors (Harford, Kecskes, \& Mansi, 2017; Ikeda, Inoue, \& Watanabe, 2017; Bumblauskas, Gemmill, Igou, \& Anzengruber, 2017; Yazdani, Zarate, Coulibaly, \& Zavadskas, 2017; Rezaei, 2018). Since selecting a dispute resolution method we most often encounter a number of criteria, that should be taken into account, a possibly successful option could be a successive discount method. For the purpose of the method all indicators are ranked in terms of their importance. Having resolved a task with respect to the first most important indicator, a limit for decreasing the indicator is established while looking for a second most important indicator, adhering to the requirement that the first indicator does not decrease below the established threshold value. The same procedure is applied to the second indicator, i.e. to establish a smaller value of the indicator that satisfies one or the other Party of the dispute. Again the same problem is being solved while complying with the requirement that the first two indicators do not exceed the established limits. The same examination procedure is applied to all indicators. The most economically advantageous dispute resolution method will satisfy all the selected intervals of all indicators.

It follows that when there are numerous indicators, they are being successively maximised by successive discount method, at the same time selecting a required discount for each of them. The method allows identifying the most rational dispute resolution method for each dispute party separately, however, this does not mean that the methods selected by each of the parties individually, and both parties will agree regarding the selection of a mutually beneficial dispute resolution.

The selection of the methods required for the most economically efficient dispute resolution method is in all cases conditions by the definition of the information available at the time when the decision is to be taken. When looking for a rational solution under the conditions of uncertainty reference is made to the Maximin rule and Maximax rule. The Maximin rule tells us to rank alternatives by their worst possible outcomes: we are to adopt the alternative the worst outcome of which is superior to the worst outcomes of the others. In other words, the Rule allows maximising a minimum gain. The alternative Maximax rule allows maximising not the minimum, but rather the maximum gain, i.e. selecting the alternative that maximises the maximum payoff available. Which of the Rules is more acceptable will depend on the level of aspirations, his risk appetite and existential optimism or pessimism. In case the environmental conditions are adversely extreme, the Maximin rule can be used according to which the outcome can be referred to as pessimistic. The most challenging task when resolving the tasks of the group is to establish the minimum expected efficiency criterion values under difference conditions for different dispute resolution alternatives. That is most often concluded using different expert methods, i.e. by subjectively assessing all the information available. In case a decision-maker believes that all conditions will be expressly favourable for him, the Maximax rule can be used. An outcome obtained by way of mathematically obtained result is referred to as optimism. For the purpose of resolving the tasks of the type, the first action is to establish, by way of expert judgement, the maximum efficiency criterion values for individual alternatives under most favourable environmental conditions, followed by a selection of the alternative generating maximum payoff. The two Rules referred to above are merged under the Hurwicz Rule that instead of the extreme pessimism and optimism values offer using their linear combination.

When resolving the tasks for selecting dispute resolution methods, solutions are sought in view of competitors in operation. In that case selecting the decision is in all cases somewhat risky, because it is not possible to define all the conditions sufficiently accurately (parties to a dispute are not always interested in disclosing to each other or to any third parties complete dispute-related information, their objectives, etc.). In this case it is highly advisable to assess a range of dispute resolution methods and select the best. Provided it is possible to project the possible operational alternatives of the parties, and the parties have access to the information about the other 
party's actions and possible results to be obtained by using one alternative of each party of the dispute, it is possible to refer to game theory methods. It nevertheless needs to be mentioned that a rational dispute resolution method can be suggested to the parties of a dispute when referring to a game theory, only provided the other player is non the less clever and makes every effort to ensure that the opponent's play-off is minimum. When the process of selecting a rational dispute resolution method encounters lack of information (in relation to forecasting market price movements, duration of contract works, the effective date of a court judgement, litigation costs, etc.), decisions are to be taken without having sufficient information. In this case an appropriate method could be the theory of statistical solutions. The selection of a rational dispute resolution method involves choosing one of the strategies: $A_{1}, A_{2}, \ldots$, $A_{m}$. The strategies shall be realised in different situations that can be marked as $S_{1}, S_{2}, \ldots, S_{n}$. Just like in the case of a game theory, the payoffs $a_{i j}$ can be calculated for any strategy pair $A_{i} S_{j}$, and identify an optimal strategy on the basis of the payoffs. The method will be applied for the purpose of selecting a dispute resolution method.

\section{Dispute settlement economy}

As the boundaries between different branches of science are getting increasingly blurred, and new emerging areas of science are not entirely independent, still have their specific research areas. Law and economics may be one of the areas and considered as an entirety that has already demonstrated in what way the legal system affects the economic life of the society (Ruge-Murcia \& Riboni, 2017; Wu, Liu, \& Qin, 2017; Simone, Barile, \& Calabrese, 2017), and in what way in relation to analysing the outcomes of the normative acts being adopted, as well as the results of court decisions, and the economic aspects that should be taken into account (Jenkins, 2017; Virlics, 2013; Garcia-de-Prado, Ortiz, \& Boubeta-Puig, 2017). The economic and the legal systems are related by reciprocal impact. The legal system affects the behaviour of individuals, and through that the legal system affects the entire economic system (Virlics, 2013). The economic system equally affects the behaviour of individuals, and, accordingly, the legal system. The economic system to the largest extent affects objectives, goals, while the legal system establishes and puts in place certain restrictions upon behaviour.
An exclusive feature of economics and law as an entirety is its ability to refer to economic models when analysing regulations, legal doctrines and legal processes (Miceli, 2004). Thus economic concepts, assumptions concerning the conduct of the society serve as a methodological base of he legal system. The possibilities of application of laws of economics in law has been within the focus of numerous researchers (Garg, 2017; Markou, Koulinas, \& Vavatsikos, 2017; Miceli, 2000, 2004; Hylton, 2002; Main \& Park, 2002). The science of economics and law as an entirety not only supplements the theoretical basis of legal doctrines analysing legal processes, but also serves as a means of projecting of possible impacts of law upon the changes in the society.

The analysis presented further will involve a mathematical analysis and cover a likely behaviour of the parties seeking to resolve disputes and finding the most economically efficient alternative of behaviour of the parties to a dispute in a pre-trial stage of the dispute.

Although a peaceful resolution of a dispute often requires significant efforts, tolerance, creativity and resilience, having understood an economic and social message of a peaceful agreement does not any longer look so impossible.

Furthermore, it should be noted that a peaceful resolution of a dispute very often is much more acceptable from the society's viewpoint, leading to savings of budgetary funds subsequently used to maintain the judicial system. However, it is understood that any parties involved in a dispute in all cases seek to satisfy their personal interests, while pushing the public interests into the background, or in even more frequent cases, entirely ignoring it.

Being aware that in most cases disputes do not end in a peaceful resolution, why does part of the disputes still reach courts.

With a view to identifying the main factors causing some of the factors for the disputes to escalate into a judicial litigation, it is appropriate to view the course of a dispute from an economist's viewpoint. For that economic models are applied to a dispute analysis - optimistic (or the model of expectations of the different parties regarding the outcome of the cases), and the asymmetric information model (Merigo, Palacios-Marques, \& Zeng, 2016; Miceli, 2004). It should be noted that the analysis will include only the disputes in relation to which any damage incurred by one party to another is not reimbursed by insurers that have provided a coverage of a third party liability, or when the insurance benefits are not sufficient to 
fully cover the loss. In the cases when the loss is fully compensated by insurers, the dispute between the parties is resolved peacefully, provided both parties agree regarding the amount of the damage. After mathematically calculating the possible cost of winning or losing the dispute, both parties would make up their minds whether to seach for ways to resolve the conflict peacefully or go for judicial settlement easier. In addition, the mathematical calculations in the article could be used in creating legal decisions support systems.

\subsection{Optimistic model}

In order to assess whether the injured party should apply to court regarding the resolution of a dispute, the party's probability to win a judicial dispute is marked as $L_{1}$, and $L_{2}$ designates the probability of the other party of the dispute to win the same dispute (in order words, $L_{2}$ represents the respondent's assessment of his probability to lose the litigation case). The amount that the court would award to the first party of the dispute in case the Party wins the case is marked as $P$, and $B_{1}$ and $B_{2}$ are the markings of respective litigation expenses of both parties.

Thus using the variables it is now possible to estimate the value of the litigation of the first party to the dispute $\left(L_{1} P-B_{1}\right)$, provided by a judgement of the court the amount awarded to its benefit is larger than the litigation expenses. In case the estimated value of the litigation is positive, it is clear that the party shall always seek judicial litigation, in case having exhausted all the other possibilities, the parties have failed to reach an amicable agreement. Being aware of the forecasts it may be assumed that a party would be satisfied with any offer S placed by the respondent for a peaceful resolution of the dispute which $S \geq L_{i} P-B_{i}$.

The estimated litigation cost of the second party of the dispute is $L_{2} P+B a$. Thus this party of the dispute would be satisfied with a peaceful resolution whose value is $S \leq L_{a} P+B_{a}$. It follows that a settlement between the Parties is possible provided there is an offer amount $\mathrm{S}$ which satisfies the condition:

$$
L_{1} P-B_{1} \leq S \leq L_{2} P+B_{2},
$$

accordingly,

$$
L_{1} P-B_{1} \leq L_{2} P+B_{2} .
$$

Thus, a peaceful resolution is possible provided the maximum amount potentially offered by the respondent is larger than the minimum amount that the potential claimant would agree to accept. The inequasion may be rearranged:

$$
\left(L_{1}-L_{2}\right) \mathrm{P} \leq B_{1}+B_{2} .
$$

In case we assume that $L_{1}=L_{2}$, i.e. if the conviction of the parties regarding their possibilities to win the dispute is equal, a peaceful resolution is possible in all cases, because the parties share an interest to avoid litigation costs. A peaceful resolution of a dispute is not guaranteed in case any of the parties firmly takes a position that:

$$
\left(L_{1}-L_{2}\right) P \leq B_{1}+B_{2} .
$$

In that case the more different are the beliefs of the parties regarding the outcome of the case, the more difficult is for them to negotiate.

Thus having performed several non-complex mathematical computations designed to assess the economic efficiency of litigation in court, it is now possible to arrive at several conclusions: First, the higher is the litigation cost which before the beginning of the litigation process is most often established only intuitively, the less acceptable is litigation. Second, the acceptability of litigation is directly proportional to the difference $L_{1}-L_{2}$ which reflects the optimistic forecasts regarding the outcome of the case. In other words, the higher probability of one party to win the dispute is higher, and the more optimistic forecasts of another party regarding the course of the dispute, the more acceptable is litigation. Third, where $L_{1}-L_{2}>0$, the larger is the amount $\mathrm{P}$ that one party expects to be awarded from the other party through litigation, the more acceptable is litigation to the Parties.

\subsection{Asymmetric information model}

Economists are most often not quite satisfied with the forecasts of litigation because such estimations do not take into account any kind of contingent expenses. Why two rational parties to a dispute having equal possibilities with respect to the outcome of the case, nevertheless fail to resolve the dispute amicably? Further, we present an analysis of a judicial litigation in view of an asymmetrical information flow. For instance, a party that had inflicted damage to another party, is most probably aware that it acts negligently,or which specific actions caused the damage, however, normally the party will not disclose such information to the injured party in the hope that the latter will not notice the damage, and if does notice, it will not be able to property assess it. Some confidential information (e.g. about the negligence of the 
party that experienced a loss, its carelessness that caused the loss) may be also available to the first party. This asymmetry of information prevents from understanding, much in advance when not knowing what information is available at the disposal at the other party, why one or the other party refuses to accept the seemingly significant discounts for a peaceful settlement, but rather seeks judicial litigation (Ayuso et al., 2015).

While seeking to analyse possible behaviour in such situation, we might assume that one party has confidential information that increases its chances to win the dispute. Let's assume that there are two types of entities that have suffered any damage: entities that have discharged their duties and obligations properly and did not contribute by their actions to inflicting damage, has significant opportunities to win the case, and assesses the possibilities (in per cent) as $L_{x}$, and the entities that have been discharging their obligations negligently, therefore has smaller possibilities to win the case and assesses them as $L_{y}$. It is understood that in all cases $L_{x}>L_{y}>0$. When being aware of their possibilities to with a case the parties can now estimate the expected compensation of the damage through the judicial litigation. The parties with significant chances to win the case would be awarded an amount of $L_{x} P-B_{1}$, while the parties with insignificant chances to win would be awarded $L_{y} P-B_{1}$, where $L_{x} P-B_{1}>L_{y} P-B_{1}$.

However, without having the information at the disposal of the entities initiating the dispute (e.g. potential claimants) the potential respondents are not in a position to identify the specific type to which the other party of the dispute belongs. Let us assume that a refers to the abundance of claimants with 'great opportunities'. Thus a potential respondent may estimate the average possibilities of the claimants to win the case:

$$
L_{\text {vid. }}=a L_{x}+(1-a) L_{y} \text {. }
$$

It follows that the expected costs of litigation of the respondent with a random claimant is $L_{\text {vid. }} P+B_{2}$. Just like in the previous random calculation models, a peaceful resolution would be also possible in this case too, if the potential respondent could offer to the potential claimant a monetary amount $\mathrm{P}$ which that claimant would prefer to accept rather than engage in litigation.

If the respondent would offer to the claimant an amount that is equal to or larger than the cost of litigation of the 'great opportunities' claimant, i.e. $L_{x} P-B_{1}$, the claimants of both types will agree with the offer, and the dispute will be resolved without any judicial litigation. Let us assume that the respondent refers to such gaming strategy whereby with a view to satisfying the claimants of both types, offers an amount $S_{d}=L_{x} P-B_{1}$, corresponding to the amount having received which the injured party would not apply to court. According to this strategy the respondent loses an amount equal to $L_{x} P-B_{1}$, and the dispute does not reach the judicial litigation stage.

However, the respondent may take measures to reduce the amount lost thereby using different strategies. Let us assume that he offers an amount that $S_{n}=L_{y} P-B_{1}$. In this case a claimant who has limited possibilities to win the case will agree with the offer, however, a respondent with significant possibilities to win the case will reject te offer, and will apply to court with a claim. This strategy of classifying the claimants into several types causes the individual negotiations with each claimant separately (a 'limited possibility' claimant will conclude the dispute with a peaceful settlement, and that with 'great possibilities' will apply to court). In case the respondent is not aware of the type of the claimant that it is offering moneys as a compensation for the damage incurred, and thus seeking to conclude the dispute amicably, its expected costs shall be:

$$
a\left(L_{x} P+B_{2}\right)+(1-a)\left(L_{y} P-B_{1}\right) .
$$

The third possible strategy would be an offer by the respondent of an amount lower than $S_{n}$ in which case the claimants of both types would reject the offer, and the dispute between the parties would most probably reach the court.

Having estimated the average possibilities for the claimants to win the case, the respondent will be seeking to conclude a peaceful agreement without exceeding the expenses that are equal to $L_{v i d} P+B_{2}$. It is not difficult to conclude that the price would be acceptable to a $L_{y}$ type claimant, however, it will not be acceptable for a 'great possibilities' claimant. Such strategy may be acceptable also to the respondent, because ordinarily it is more economical for it to meet the interests of a claimant of at least one type, because that allows saving the costs of litigation with the claimant of the type.

As has been shown, a dispute with a 'great opportunities' claimant under an asymmetrical information model, reaches the court in all cases, when the respondent opts for the claimants exclusion strategy instead of the optimistic strategy. In the meantime the respondent will most probably opt for this strategy, in case its probable expenses (6) are smaller than the expenses according to the game strategy $L_{x} P-B_{1}$, i.e. if: 


$$
\frac{1-a}{a}\left(L_{x}-L_{y}\right) P>B_{1}+B_{2} .
$$

It might be noticed that it is extremely similar to the conditions of an optimistic model, which allows arriving at several analogous conclusions: For instance, both models assume that the higher is litigation price $B_{1}+B_{2}$, the less desirable is litigation. Furthermore, both models allow a conclusion that the overweight of the information at the disposal of one of the parties changes the price of a peaceful resolution (irrespective of the fact that the nature of information may change). However, when a dispute evolves into a judicial litigation, each of the models allows making different conclusions.

\section{Incentive to file a claim}

Having analysed, from an economic viewpoint, the possibilities for concluding a peaceful resolution, it is appropriate to analyse the incentives for one of the dispute parties to file a claim in court. As has been earlier shown the injured party will in most cases file a claim if the expected benefit from the litigation exceeds its costs. The actual benefit of the injured party from the litigation will depend on the outcome of the examination of the claim at court.

A party considering a possibility to apply to court with a claim, shall pass a decision to do so if the monetary benefit $L_{1} P-B_{1}$ from litigation exceeds the litigation costs $f$, while the party which expects to settle the dispute without litigation, shall file a claim to court in case the price of a peaceful resolution price $S$ exceeds $f$. The present paper does not aim at establishing any more specific price of peaceful resolution, because in reality such price is established by way of negotiations. However, it is safe to assume that a reasonable injured party will not agree with a peaceful agreement condition, when the amount offered is less than the party expects to be awarded by way of negotiations. In other word, $S \geq L_{1} P-B_{1}$.

The injured party normally will decide whether it is reasonable to go into litigation, by comparing its own expenses and the payoff it expects to be awarded in a specific case. An equally important question of the importance of the decision from the societal viewpoint. We would be able to answer the question only having carefully examine the functions that encourage individuals to act in a socially acceptable manner. For example, in tort law the threat to be filed a claim prompts to the violators to refer to efficient protection measures with a view to avoiding accidents. The decision of an injured party regarding the litigation process does not necessarily coincide with a rational decision from the public' view point.

For instance, we might as well analyse a simple model, where one party of a civil that may potentially incur damage to the other party, has to make a choice between 'take precautionary measures' and 'not to take precautionary measures'. In case the entity decides not to take any precautionary measures, the probability of threat of damage shall be $n_{n}$, however, in case the entity takes the precautionary measures and therefore incur the costs $\mathrm{x}$, the threat will be reduced and equal to $n_{a}<n_{n}$. The party to which the damage is inflicted, the loss shall be equal in all cases, and shall be marked as $N$. The litigation expenses of the injured party shall be $L_{1}$, and that of the perpetrator $-L_{2}$.

Let us look into the social value of litigation. In case the injured party files a claim, and the perpetrator responds by taking precautionary measures, the economic expression of the social value shall be:

$$
x+n_{a}\left(N+L_{1}+L_{2}\right),
$$

which includes the precautionary measures costs, litigation costs and the compensation for the loss suffered. And conversely,where the injured party does not apply to curt, the perpetrator is not and will not be taking the precautionary measures, the social value of such behaviour can be expressed as:

$$
n_{n} N
$$

It follows that the behaviour is socially acceptable if (7) is less than (8), or, otherwise:

$$
x+n_{a}\left(L_{1}+L_{2}\right)<\left(n_{n}-n_{a}\right) N .
$$

For the purpose of interpretation of the condition it is safe to say that litigation is acceptable, in case the precautionary measures price and the expected litigation costs are lower than the incurred damage. However, a party that has suffered loss because of the actions of the another party will most probably appeal to court, if $N>L_{1}$, which does not always coincide with the condition of social acceptability of litigation. The difference between an individual and the social incentive to refer to litigation appears for two reasons: first, the injured party is not concerned with the litigation costs that will be charged to the violator; 
second, the injured party ignores the fact that any disputes between parties regarding the damage are in incentive for violators to invest in third party liability insurance. Such considerations lead to a situation when ignoring the social value of litigation, there is a danger for emerging some extremities: the parties may seek litigation process in the case of each dispute, or decide not to apply to courts whatsoever, despite the fact that their interests are heavily damaged.

\section{Conclusions}

The application of the optimistic model in relation to assessing the reasonableness of litigation, allows a conclusion that the acceptability of litigation is directly proportionally to the price of litigation, the value of the difference between the forecasts of the parties to the dispute, and the amount of the possible damage (claim amount).

The calculations performed have shown that in the case of an optimistic model the parties always have a possibility to resolve the dispute by a peaceful resolution, provided their projections regarding the outcome of the case coincide.

It has been concluded that a party that for the purpose of assessing the reasonableness of litigation has selected the asymmetrical information model, will most often achieve a peaceful resolution with a 'small possibilities' claimant only.

Given calculations can be used in mediators' practice when the parties do not decide to end the conflict peacefully.

The computations also showed that the decision of the parties to a dispute to litigate or conclude the dispute by a peaceful resolution is not always acceptable from the societal viewpoint: from the public viewpoint, the litigation price may be higher than its social value.

The computations carried out for the purpose of the present paper allows a conclusion that the methodology for the calculation of the efficiency of strategies could be used for the purpose of developing specialised legal decisions support systems facilitating selecting the most efficient dispute resolution method. Moreover, the calculations can be successfully adapted in judicial mediation procedures.

\section{References}

Ayuso, M., Bermudez, L., \& Santolino, M. (2015). The dynamics of one-sided incomplete information in motor disputes. International Review of Law and Economics, 41, 77-85.

https://doi.org/10.1016/j.irle.2014.11.004
Bench-Capon, T., \& Prakken, H. (2008). Intorducing the logic and law corner. Journal of Logic and Computation, 18(1), 1-12. https://doi.org/10.1093/logcom/exm060

Bielen, S., Peeters, L., Marneffe, W., \& Vereeck, L. (2017). Backlogs and litigation rates: Testing congestion equilibrium across European judiciaries. International Review of Law and Economics, 53, 9-22. https://doi.org/10.1016/j.irle.2017.09.002

Brophy, E. (2014). Health care decision-making, CM and the law. Advances in Integrative Medicine, 1(1): 40-43. https://doi.org/10.1016/j.aimed.2013.08.002

Bumblauskas, D., Gemmill, D., Igou, A., \& Anzengruber, J. (2018). Smart Maintenance Decision Support Systems (SMDSS) based on corporate big data analytics. Expert Systems with Applications, (90), 303-317.

Cooter, R. D., \& Rubinfeld, D. L. (1989). Economic analysis of legal disputes and their resolution. Journal of Economic Literature, (27), 1067-1097.

Garcia-de-Prado, A., Ortiz, G., \& Boubeta-Puig, J. (2017). COLLECT: COLLaborativE Con Text-aware service oriented architecture for intelligent decision-making in the Internet of Things. Expert Systems with Applications, 85, 231-248.

https://doi.org/10.1016/j.eswa.2017.05.034

Garg, H. (2017). Novel intuitionistic fuzzy decision making method based on an improved operation laws and its application. Engineering Applications of Artificial Intelligence, 60, 164-174. https://doi.org/10.1016/j.engappai.2017.02.008

Harford, J., Kecskes, A., \& Mansi, S. (2017). Do long-term investors improve corporate decision making?. Journal of Corporate Finance, 50, 424-452. http://doi. org/10.1016/j.jcorpfin.2017.09.022

Heyes, A., Rickman, N., \& Tzavara, D. (2004). Legal expenses insurance, risk aversion and litigation. International Review of Law and Economics, 24(1), 107-119. https://doi.org/10.1016/j.irle.2004.03.007

Hylton, K. N. (2002). Asymetric - information model of litigation. International Review of Law and Economics, 22(2), 153-175. https://doi.org/10.1016/S0144-8188(02)00085-6

Ikeda, N., Inoue, K., \& Watanabe, S. (2017). Enjoying the quiet life: Corporate decision-making by entrenched managers. Journal of the Japanese and International Economies. https://doi.org/10.3386/w23804

Jenkins, V. (2017). Protecting the natural and cultural heritage of local landscapes: Finding substance in law and legal decision making. Land Use Policy, (73), 73-83.

Main, B. G. M., \& Park, A. (2002). The impact of defendant offers into court on negotiation in the shadow of the law: experimental evidence. International Review of Law and Economics, 22(2), 177-192. https://doi.org/10.1016/S0144-8188(02)00086-8

Markou, Ch., Koulinas, G. K., \& Vavatsikos, A. P. (2017). Project resources scheduling and levelling using MultiAttribute Decision Models: Models implementation and case study. Expert Systems with Applications, 77, 160-169. https://doi.org/10.1016/j.eswa.2017.01.035

Merigo, J. M., Palacios-Marques, D., \& Zeng, S. (2016). Subjective and objective information in linguistic multicriteria group decision making. European Journal of Operational Research, 2(248), 522-531. https://doi.org/10.1016/j.ejor.2015.06.063

Miceli, T. J. (2000). Deterrence, litigation costs, and the statute of limitations for tort suits. International Review of Law and Economics, 20(3), 383-394. https://doi.org/10.1016/S0144-8188(00)00038-7 
Miceli, T. J. (2004). The economic approach to law. Stanford University Press. 379 p.

Murtoaro, J., \& Kujala, J. (2007). Project negotiation analysis. International Journal of Project Management, 25(7), 722-733.

https://doi.org/10.1016/j.ijproman.2007.03.002

Okudaira, H. (2018). The economic costs of court decisions concerning dismissals in Japan: Identification by judge transfers. International Review of Law and Economics, 53, 60-75. https://doi.org/10.1016/j.irle.2017.09.006

Rezaei, J. (2018). Piecewise linear value functions for multicriteria decision-making. Expert Systems with Applications, 98, 43-56. https://doi.org/10.1016/j.eswa.2018.01.004

Ruge-Murcia, F., \& Riboni, A. (2017). Collective versus individual Decision-Making: A case study of the Bank of Israel Law. European Economic Review, 93, 73-89. https://doi.org/10.1016/j.euroecorev.2017.01.003

Schweizer, U. (2016). Efficient incentives from obligation law and the compensation principle. International Review of Law and Economics, 45, 54-62. https://doi.org/10.1016/j.irle.2015.11.005

Simone, C., Barile, S., \& Calabrese, M. (2018). Managing territory and its complexity: a decision-making model based on the viable system approach (VsA). Land Use Policy, 72, 493-502.

https://doi.org/10.1016/j.landusepol.2017.12.070

Virlics, A. (2013). Investment decision making and risk. Procedia Economics and Finance, 6, 169-177. https://doi.org/10.1016/S2212-5671(13)00129-9

Wu, T., Liu, X., \& Qin, J. (2018). A linguistic solution for double large-scale group decision-making in E-commerce. Computers \& Industrial Engineering, 116, 97112. https://doi.org/10.1016/j.cie.2017.11.032

Yazdani, M., Zarate, P., Coulibaly, A., \& Zavadskas, E. K. (2017). A group decision making support system in logistics and supply chain management. Expert Systems with Applications, 88, 376-392. https://doi.org/10.1016/j.eswa.2017.07.014

Yoojung, Y., Hastak, M., \& Cho, K. (2017). Preference clustering-based mediating group decision-making (PCMGDM) method for infrastructure asset management. Expert Systems with Applications, 83, 206-214).

Zhang, N., Gong, Z., \& Chiclana, F. (2017). Minimum cost consensus models based on random opinions. Expert Systems with Applications, 89, 149-159. https://doi.org/10.1016/j.eswa.2017.07.035 